-among others-with interactions between phenols and amine monolayers, catalytic oxidation of ethylene, the plastic and vinoelastic behaviour of solid-liquid dispersions and polymer gels, and the kinetics and mechanism of polymerization reactions. The last-named topic has formed the basis of Prof. Pepper's interests in Trinity College, Dublin, most of his work being in the field of polymer solutions or in studies of the kinetics and mechanism of cationic polymerization. His research school has revealed some of the special characteristics of these reactions, notably the effect of solvents both through their dielectric behaviour and as co-catalysts. His work has focused attention on the considerable kinetic differences between these ionic polymerizations and free-radical polymerizations. It is true to say that contemporary theory in this field is largely based on ideas developed in Prof. Pepper's research group.

\section{U.S. National Bureau of Standards: New Appoint-} ments:

Mr. Martin T. Decker

Mr. Martin T. DECKER has been appointed chief of the Tropospheric Measurements Section of the National Bureau of Standards Laboratories at Boulder (Colorado). Mr. Decker joined the Bureau staff in 1949 , his early work being in the area of tropospheric forward scatter of radio waves. More recently his research has been primarily in air-to-ground communications, including air navigation and airborne television studies, especially the prediction of reliability. He has also made studies of the obstructing effects of various materials on radio waves at VHF, UHF and SHF. Born in Byron, Nebraska, in 1927, Mr. Decker received his B.S. degree in electrical engineering from the University of Nebraska in 1950. He has continued his engineering studies at the University of Colorado.

Mr. John L. Hague

Mr. JoHN I. HAGUE, a national authority in the field of analytical chemistry, has been appointed chief of the Standard Reference Materials Section. Mr. Hague had been acting chief of the predecessor section, Analytical Chemistry, since March 1960. The Standard Reference Materials Section will play an important part in the Bureau's standard materials programme. In this programme, the Bureau makes available for distribution to science and industry more than 550 different standards of metals, ores, ceramics, chemicals, hydrocarbons, and more recently added radioactive materials, uranium isotopes, lithium ores, aluminium refractories, and phosphor materials. Standard materials are used to check, evaluate and standardize methods of analysis and analytical techniques and substances, and to develop new and improved methods and instruments. Mr. Hague joined the Bureau staff in 1930 as a laboratory apprentice. In 1932 he transferred to the Norfolk Shipyard and three years later was in charge of the Foundry Control Laboratory for ferrous and nonferrous alloys. He returned to the National Bureau of Standards in 1935 and in 1951 became assistant chief of the Analytical Chemistry Section. Born in Kansas City, Missouri, in 1912, Mr. Hague received his B.S. degree in chemistry in 1938 from George Washington University and has done graduate work there. In 1958, Mr. Hague received the Department of Commerce Meritorious Service Award "for outstanding original contributions to methods of analysis necessary for controlling the production of complex metal alloys".
Mr. John K. Taylor

DR. JoHN K. TAYLOR, research chemist, whose entire 32-year professional career has been with the National Bureau of Standards, has been appointed chief of the Applied Analytical Research Section of the Bureau's Analytical and Inorganic Chemistry Division. The Applied Analytical Research Section is concerned with the development and application of methods for the analysis and characterization of solids, liquids and gases. Both classical and instrumental methods of analysis are employed, using both macro- and micro-techniques. The Section also provides analytical consultation services and assistance for other Bureau programmes. A major part of Dr. Taylor's work at the National Bureau of Standards has been concerned with the application of physical methods to chemical analysis, including the polarographic method and the limitations of voltammetric processes. Recently he has conducted research in high-precision coulometric methods of analysis. Dr. Taylor has written numerous papers on these subjects, and in 1960 was awarded the Department of Commerce Silver Medal in "recognition of his contributions to accurate electrochemical methods of analysis". Other areas of research interest for Dr. Taylor have included refractometry methods for separation of isotopes, and a programme for providing a series of uranium isotope standards. This last has consisted of high-precision analysis of uranium compounds and the blending of highly purified isotopic species for mass spectrographic analysis. Born in Mt. Ranier, Maryland, in 1912, Dr. Taylor received his B.S. in chemistry from George Washington University in 1934. He was awarded his M.S. and Ph.D. from the University of Maryland in 1938 and 1941, respectively. Throughout his professional life, Dr. Taylor has been an active supporter of science education. $\mathrm{He}$ is a member and past chairman of the Joint Board on Science Education of the Washington Academy of Sciences and is editor of The Reporter, a news-letter for science and mathematics teachers.

\section{Public Investment and Export}

UNDER the title "Public Investment and Export" an article by Sir Walter Benton Jones, Bart., which originally appeared in the Times Review of Industry, March 1961, has been, with the addition of some figures for public spending 1950-59, issued as a pamphlet (Pp. 7. Grantham: Sir Walter Benton Jones, Irnham Hall, 1961). Sir Walter asks the leading question: Has Britain reached a level of public spending which may jecpardize her power to compete in the expanding export markets of the world, which may soon become more competitive than at any time in history? Pointing out that public spending has risen from $£ 3,692$ million in 1950 to $£ 5,099$ million in 1955 and $£ 6,237$ million in 1959 , whereas exports increased by 33 per cent in the first period and only 16 per cent in the second, compared with increases of 49 per cent and 20 per cent, respectively, in world exports, 52 per cent and 13 per cent, respectively, for the United States, and 21 per cent and 33 per cent for West Germany, he suggests that the high level of our public spending may be handicapping our exports. Sir Walter suggests that since Parliament ultimately fixes and controls public expenditure, Parliament should be concerned to regulate the level of public expenditure by public income after due regard to possible effects of taxation on production and export, and that what is primarily 